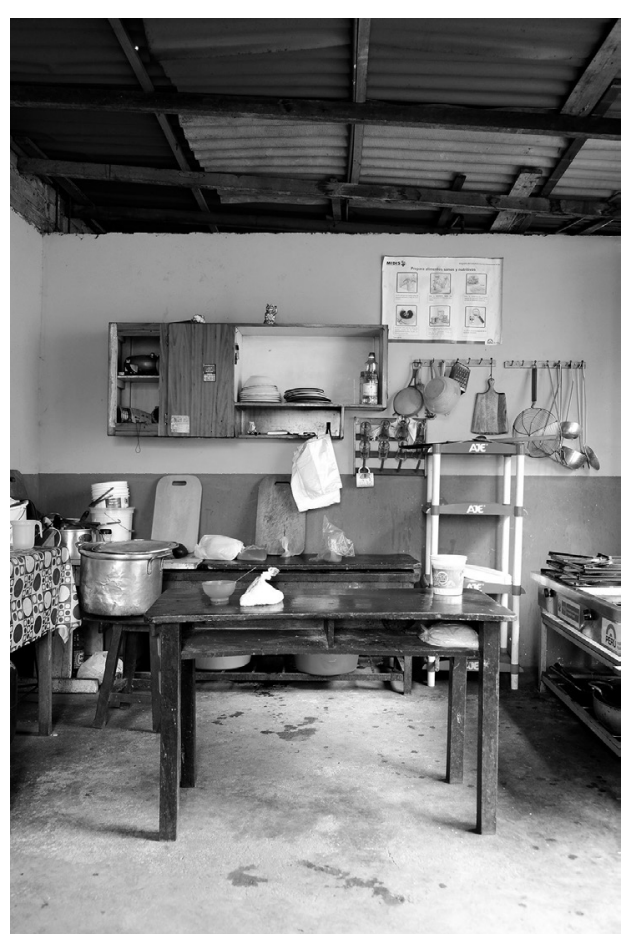

\title{
Vivir sin cocina
}

\section{Anna Puigjaner}

Recibido 2019.09.23 ::: Aceptado 2019.09.25

DOl: 10.5821/palimpsesto.20.8954

Persona de contacto: anna@maio-architects.com

ORCID: https://orcid.org/0000-0002-7822-4931

Departamento de Proyectos Arquitectónicos de la ETSA, Universitat Politècnica de Catalunya (UPC)

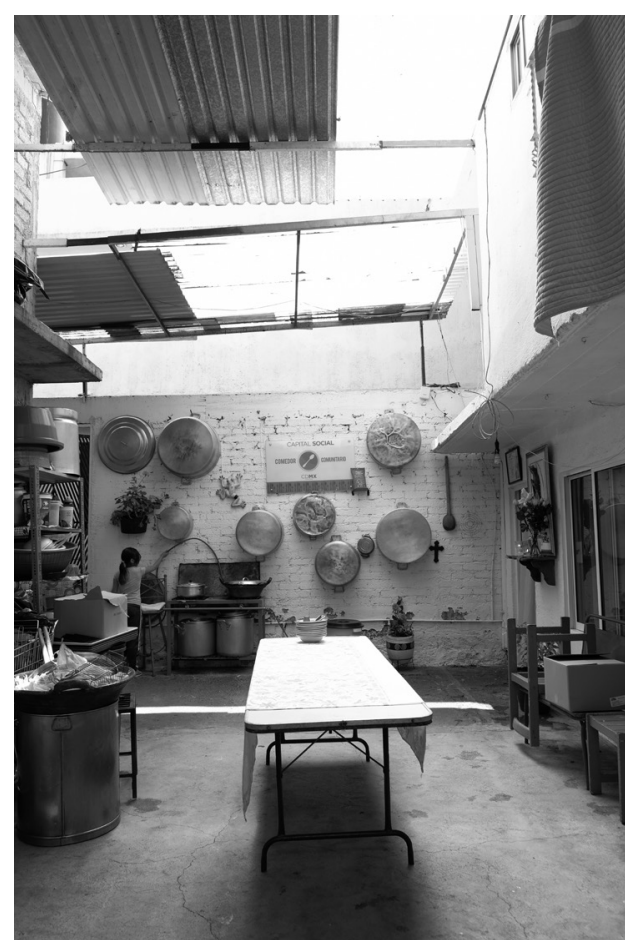

Qué ocurriría si eliminásemos la cocina de nuestras casas? Hay algo provocativo y a la vez revelador en el acto de suprimir la cocina del espacio doméstico. El rechazo social generalizado que a menudo produce esa propuesta, nos puede permitir entender lo profundamente arraigadas que se encuentran algunas de nuestras ideas -y afectos- sobre ese espacio doméstico. Pocos años después de formar parte de la Cátedra Blanca, empecé una investigación bajo la tutela de Xavier Monteys acerca de una tipología de vivienda sin cocina que surgió a finales del s.XIX en la ciudad de Nueva York, que me permitió entender e papel fundament definición histórica de la idea de hogar y de familia; $y$, en consecuencia, en la creación de relaciones de género asimétricas dentro de la esfera doméstica. No es difícil constatar cómo se ha forjado una imagen tecno-optimista de la cocina como un espacio en el que, supuestamente, la mujer ha conseguido llevar a cabo fluidamente todas las tareas domésticas gracias a la ayuda de factores tales como un diseño optimizado o un continuo progreso tecnológico, un sinfín de electrodomésticos salvíficos que no deja de anunciarse desde hace décadas y que, más que acabar con las tareas domésticas, las perpetúa bajo la promesa de su siempre inminente desaparición.

La cocina es el ámbito donde el trabajo doméstico ha perdido progresivamente su valor económico y se ha convertido en un Labour of Love (trabajo por amor), según la definición de Silvia Federici, dándose por sentado un sistema de cuidados -eminentemente femenino-, donde el valor social suplanta al económico. Este tipo de transformaciones no solo hizo que todo un sector de la sociedad -el femenino- fuese económicamente y socialmente dependiente, sino que también, a través de un aislamiento progresivo, perdiera su capacidad de acción políica.

Pero más allá de entender la cocina como un aparato de perpetuación de clichés, la mera toma de conciencia de que esas formas ideológicas contenidas en lo doméstico son, al fin y al cabo, construcciones culturales, es el primer paso que puede permitirnos entender tanto su reversibilidad como pensar en las posibilidades reales de cambio. Los valores asociados a lo domestico se encuentran en permanente transformación, y entre ellos, quizás los asociados a la cocina sean precisamente aquellos potencialmente más capaces de transgredir radicalmente los roles de relativos a las estructuras de trabajo doméstico.

Difícilmente podemos pensar la cocina de forma aislada, separada de una extensa red de relaciones urbanas, sociales y políticas. Frente a la institucionalización del Labour of Love, algunas propuestas de construcción de la cocina desde lo colectivo han intentado en diferentes contextos reformular las condiciones laborales y sociales preestablecidas. Hace dos años inicié un viaje alrededor del mundo para registrar algunos casos paradigmáticos de cocinas compartidas o colectivas. Pese a sus orígenes y naturalezas diversas, todas ellas mantienen un común denominador. La translación de la cocina más alá de los limites preestablecidos de la casa extiende lo doméstico fuera del ámbito privado. Un gesto que permite no sólo que esta esfera se expanda - la domesticación del espacio urbano - sino que al mismo tiempo hace explícitos los límites cada vez más difusos entre lo público y lo privado, entre la casa y la ciudad. Siguiendo casuísticas y motivaciones extraordinariamente distintas, con esa expansión de lo doméstico más a en público y aquello que hasta el momento quedaba limitado al ámbito cercano, a lo familiar, acentúa su carácter político y potencialmente transformador.

. https://www.e-flux.com/architecture/overgrowth/221624/ bringing-the-kitchen-out-of-the-house/ https://www.e-flux.com/architecture/future-public/151948/ kitchen-stories/

ANNA PUIGJANER es Doctora Arquitecta y

Profesora Asociada del Departamento de Proyectos Arquitectónicos en Columbia GSAPP.

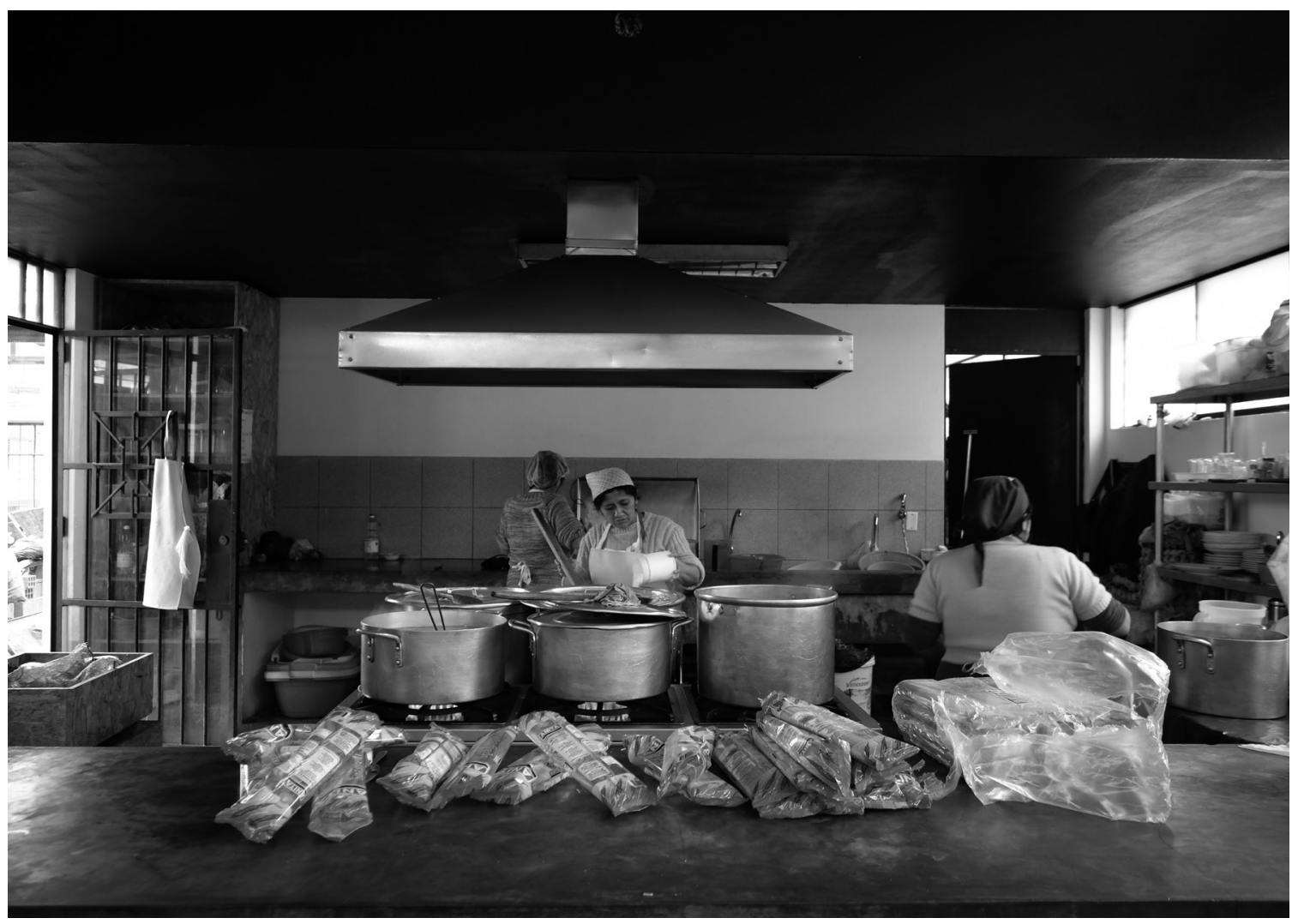

